\title{
The Effect of Intrathecal Meperidine on Maternal and Newborn Outcomes After Cesarean Section: A Systematic Review and
}

\section{Meta-Analysis Study}

\author{
Molouk Jaafarpour ${ }^{1}$, Ziba Taghizadeh ${ }^{2}$, Elham Shafiei ${ }^{3,{ }^{*}}$, Aminolah Vasigh $^{4}$ and Kourosh Sayehmiri ${ }^{5}$ \\ ${ }^{1}$ Department of Reproductive Health, Nursing and Midwifery Faculty, Tehran University of Medical Sciences, Tehran, Iran \\ ${ }^{2}$ Nursing and Midwifery Care Research Center, Tehran University of Medical Sciences, Tehran, Iran \\ ${ }^{3}$ Clinical Research Development, Mostafa Khomeini Hospital, Ilam University of Medical Sciences, Ilam, Iran \\ ${ }^{4}$ Department of Anaesthesiology, Medicine Faculty, Ilam University of Medical Sciences, Ilam, Iran \\ ${ }^{5}$ Biostatistics Department, Modelling in Health Research Center, llam University of Medical Sciences, llam, Iran \\ "Corresponding author: Clinical Research Development, Mostafa Khomeini Hospital, Ilam University of Medical Sciences, Ilam, Iran. Email: eshafiei1524@gmail.com
}

Received 2019 December 21; Revised 2020 February 22; Accepted 2020 February 25.

\begin{abstract}
Context: Spinal anesthesia is the most preferred method for cesarean section. This meta-analysis was performed to determine the effect of minimum and maximum intrathecal doses of meperidine (pethidine) [ 5 to $40 \mathrm{mg}$ ] on the maternal and newborn outcomes after cesarean section.

Evidence Acquisition: The data were collected through the systematic search in the ISI, PubMed, Scopus, Google Scholar, Barakat, MagIran, SID, Irandoc, and EMBASE medical databases. Eighteen clinical trial studies with 1,494 patients were included.

Results: Patients who had received intrathecal meperidine had experienced lower shivering, relative risk $[\mathrm{RR}]=0.34(95 \% \mathrm{CI}=0.23$, $0.48)$ and longer analgesia, [standard mean difference $(\mathrm{SMD})]=7.67(95 \% \mathrm{CI}=1.85,13.49)$ after the surgery. Moreover, $\mathrm{RR}$ of nausea $=$ $1.37(95 \% \mathrm{CI}=1.13,1.66)$, vomiting $\mathrm{RR}=2.02$ ( $95 \% \mathrm{CI}=1.28,3.20)$, and pruritus $\mathrm{RR}=9.26(95 \% \mathrm{CI}=4.17,20.58)$ was higher in the pethidine group than in the control group. There was no statistically significant difference in the Apgar score at one-minute RR $=0.99(95 \% \mathrm{CI}$ $=0.9,1.09)$, at five-minute $\mathrm{RR}=0.93(95 \% \mathrm{CI}=0.87,1.08)$, maternal hypotension $\mathrm{RR}=1.00(95 \% \mathrm{CI}=0.87,1.15)$, and maternal sensory and motor blockade durations, $\mathrm{SMD}=-1.72(95 \% \mathrm{CI}=-3.78 .0 .34)$ and $\mathrm{SMD}=-4.38(95 \% \mathrm{CI}=-9.19,0.44)$, respectively in the two pethidine and control groups.

Conclusions: Intrathecal meperidine can reduce shivering and increase the duration of postoperative analgesia, though it increases the relative risk of nausea, vomiting, and pruritus. No significant difference was found both in the Apgar score, maternal hypotension, and duration of the motor and sensory block.
\end{abstract}

Keywords: Meperidine, Spinal, Injections, Cesarean Section, Mothers

\section{Context}

Caesarean section is one of the major surgeries in women with an increasing trend in developed and developing countries (1-4). The rate of cesarean delivery in the United States and the European countries has been reported $32.7 \%$ and $21.1 \%$, respectively (5). The rate of the cesarean section in Iran ranges from $26 \%$ to $66.5 \%$ according to various studies (6). The world's report for the cesarean sections among 15 countries has been about $18.6 \%$ (7). Spinal anesthesia is the best-preferred method for anesthesia in patients with emergency and elective cesarean section due to a series of advantages such as rapid onset, high success rate, reduced side effects on the mother and the fetus, safety, and efficacy (8-11).
According to the Royal College of Obstetricians and Gynecologists, the cesarean section should be carried out under an urgent appropriate circumstance to eliminate the risks to the embryos and guarantee the mother's safety (12). Any anesthetic drug or anesthetic method for the cesarean section should have features such as maintaining the hemodynamic stability of the mother, rapid induction and possessing the least effects on the newborn Apgar score (13). Cesarean section is of much sensitivity due to its adverse effects and complications on the mother and the baby. For example, moderate to severe pain after the cesarean section reported by $75 \%$ of the mothers is one of the major concerns of the mothers after the cesarean delivery (14). 
Postoperative complications, such as shivering with a prevalence of about 56.7\% and vomiting with 9 to $56 \%$ are the main concerns for anesthesiologists in the recovery room. Postoperative shivering can increase oxygen consumption and carbon dioxide production by up to $400 \%$. On the other hand, nausea and vomiting can prolong the recovery (15-18). The neonatal Apgar score after birth is one of the determining factors of mortality and general wellbeing of the newborn. In this regard, the type of drug used for the cesarean section is very important in the Apgar score of the cesarean section (19).

Pethidine is an intermediate lipid-soluble opioid with both a postoperative analgesic mechanism and a sensory block which is known as the only substance used in the cesarean section under spinal anesthesia. However, pethidine can cause a number of complications such as hypotension, vomiting and respiratory depression $(20,21)$.

Considering the controversial results of various studies about different doses of intrathecal pethidine on the mother and the newborn this meta-analysis was conducted to determine the effect of minimum and maximum intrathecal doses of pethidine ( 5 to $40 \mathrm{mg}$ ) on the cesarean section under spinal anesthesia.

\section{Evidence Acquisition}

This is a meta-analysis and systematic review of the effects of intrathecal meperidine on maternal and newborn outcomes after cesarean section under spinal anesthesia that was carried out according to preferred reporting items for systematic reviews and meta-analyses (PRISMA) guidelines (22).

\subsection{Search Strategy}

We performed a systemic search without any language restrictions from 1 September 2018 to 7 December 2018 (literature searches between 1990 to 2018). Our searching medical databases for this study included ISI, PubMed, Scopus, Google Scholar, Barakat, MagIran, SID, Irandoc, and EMBASE. The keywords used for medical subjects included meperidine, pethidine, meperidine hydrochloride, cesarean section, pethidine and cesarean, spinal anesthesia, Apgar score, intrathecal anesthesia, subarachnoid anesthesia, regional anesthesia, lumbar anesthesia, intrathecal meperidine, intrathecal pethidine, postoperative shivering, postoperative complication.

Two researchers at the same time conducted a study selection and data extraction of the effect of the minimum and maximum dose ( 5 to $40 \mathrm{mg}$ ) of intrathecal pethidine on maternal and newborn outcomes after cesarean section and independently evaluating the quality of the articles.
Inclusion criteria were the use of the minimum and maximum dose of intrathecal pethidine (5 to $40 \mathrm{mg}$ ) in cesarean section under spinal anesthesia, matching of the drugs were used with pethidine, measuring one of the following parameters: shivering, nausea, vomiting, hypotension, pruritus, Apgar score, time of sensory block, time of motor block and analgesia duration. Exclusion criteria were the use of local anesthesia, non-elective surgery, combined different opioids, studies that were unrelated to the subject and studies that full text was unavailable.

\subsection{PICO}

Population included cesarean section under spinal anesthesia that received intrathecal meperidine. Patients were divided into pethidine and control groups. The outcome included: shivering, nausea, vomiting, hypotension, pruritus, Apgar score, time of sensory block, time of motor block, and analgesia duration.

\subsection{Statistical Analysis}

The following data were extracted from the studies: the authors' names, the year of publication, the type of study, the sample size of study groups, country of publication, prevalence of shivering, nausea, vomiting, hypotension, pruritus, and Apgar score at one and five minutes, time of sensory block, time of complete motor block, and analgesia duration.

Effect size parameters consisted of relative risk (RR) and standard mean difference (SMD) in this study. The results of studies pooled using random effects models and fixed effects models. Heterogeneity of studies checked using $\mathrm{Q}$ test, $\mathrm{I}^{2}$ index and meta-regression. Publication bias checked using funnel plot and Egger test. P value $<0.05$ was considered statistically significant. Data were analyzed with STATA ver. 11.2.

\section{Results}

Selection of Articles: in this review, 50, 30, and 93 articles were obtained from PubMed, ISI, SCOPUS and other databases, respectively, according to the keywords. After excluding the duplicates, 50 articles remained. Looking at the summary of the articles, 20 articles that were not related to the topic were deleted as well. By reading the full text of the articles, 5 articles were eliminated because of the lack of sample size and 7 more others were excluded because of the unspecified drug usage. Finally, 18 articles were entered into the analysis (Figure 1).

Eighteen articles that had examined factors such as nausea, vomiting, shivering, hypotension, pruritus, newborn Apgar score, duration of the postoperative analgesia, 


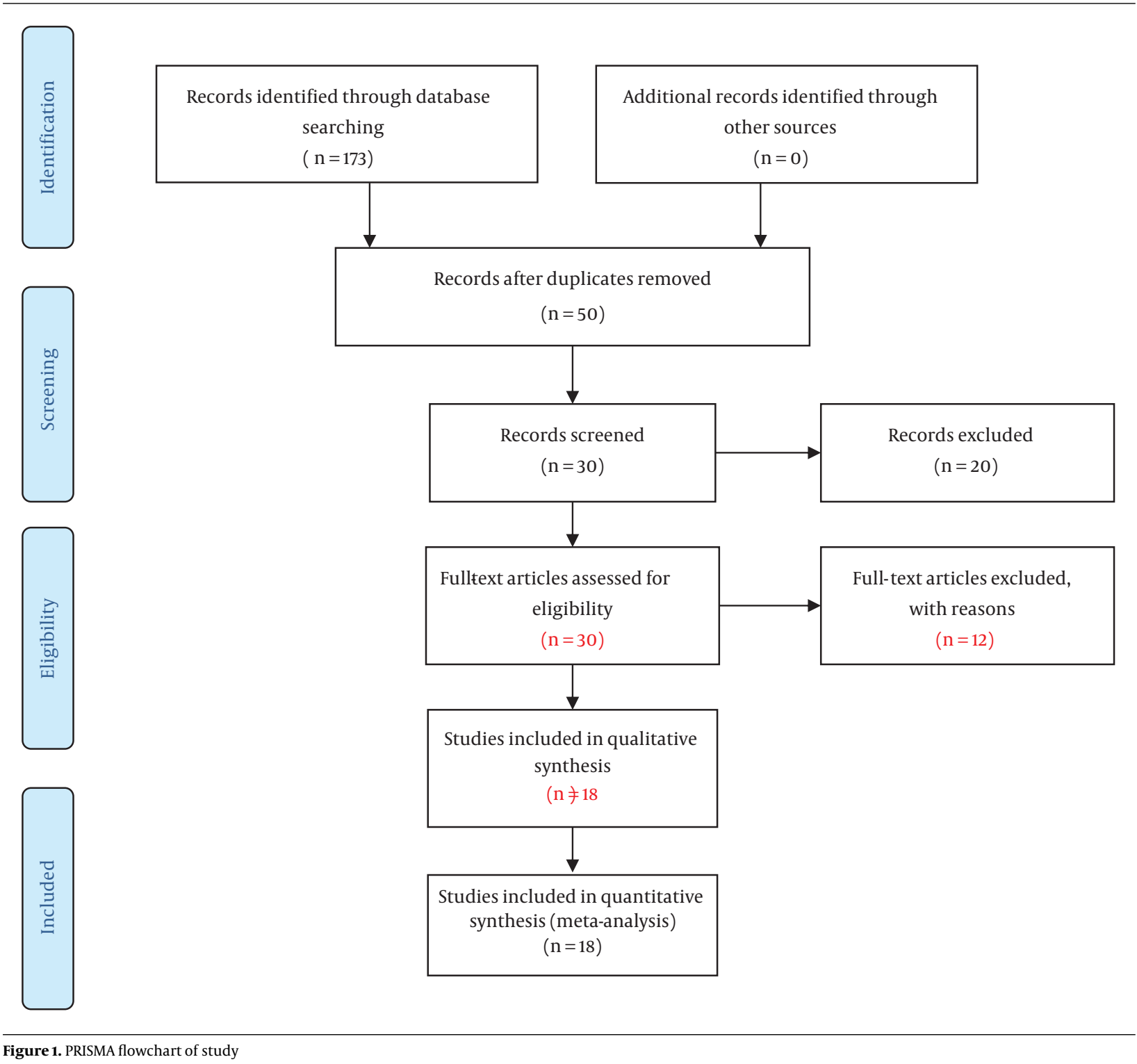

Figure 1. PRISMA flowchart of study

and duration of the complete sensory, and motor block are presented in Tables 1 and 2. The length of each segment shows the confidence interval. The middle of the line represents the relative risk for the point estimation. The Rhombus sign represents the combined result of all the studies. The reason for the cut-off point of $20 \mathrm{mg}$ in this study was due to high and low effects of pethidine and statistically similar placement of studies with different doses on both sides of the cut-off point. The sample size of the studies was 1,494 . Out of the 12 studies with a dose of $\leq$ $20 \mathrm{mg}$, 3 studies were not meaningful in terms of postoperative shivering. On the whole, the effect of the intrathecal pethidine with a dose of $\leq 20 \mathrm{mg}$ on the postopera- tive shivering was significant. The weight of the Shrestha et al. (23) study was more. Those who had received pethidine had lower shivering of $66 \%$. The studies with a greater confidence interval (CI) had less weight and were less precise. The effect of the intrathecal pethidine with a dose of $>20 \mathrm{mg}$ on the postoperative shivering in 8 studies was significant except for one case. Patients who had received intrathecal pethidine at a dose of $>20 \mathrm{mg}$ showed lower shivering of $82 \%$ (Table 3 and Figure 2).

No significant effect was observed in eight of the studies on the effect of the intrathecal pethidine with doses less and more than $20 \mathrm{mg}$ on the maternal hypotension (Table 3). Out of the 12 studies, the effect of the intrathecal pethi- 


\begin{tabular}{|c|c|c|c|c|c|c|c|c|c|c|c|}
\hline \multirow{2}{*}{ Authors' Names } & \multirow{2}{*}{ Year } & \multirow{2}{*}{ Country } & \multirow{2}{*}{ Dose, $\mathrm{mg}$} & \multirow{2}{*}{$\begin{array}{l}\text { Pethidine/Control } \\
\quad \text { (Number) }\end{array}$} & \multicolumn{7}{|c|}{ Variables } \\
\hline & & & & & Shivering & Nausea & Vomiting & Hypotension & Pruritus & $\begin{array}{c}\text { Apgar }>7 \text { at } 1 \\
\text { min }\end{array}$ & $\begin{array}{c}\text { Apgar }>7 \text { at } 5 \\
\text { min }\end{array}$ \\
\hline \multirow{4}{*}{ Shami et al. (10) } & \multirow{4}{*}{2016} & \multirow{4}{*}{ Iran } & \multirow{2}{*}{5} & $\begin{array}{l}\text { Pethidine }(\mathrm{n}= \\
50)\end{array}$ & $11(22)$ & $25(50)$ & $13(26)$ & $33(66)$ & $3(6)$ & - & - \\
\hline & & & & Control $(\mathrm{n}=50)$ & $25(50)$ & $19(38)$ & $6(12)$ & $34(68)$ & 0.00 & - & - \\
\hline & & & \multirow{2}{*}{10} & $\begin{array}{l}\text { Pethidine }(\mathrm{n}= \\
50)\end{array}$ & $2(4)$ & $27(54)$ & $13(26)$ & $37(74)$ & $13(26)$ & - & - \\
\hline & & & & $\operatorname{Control}(\mathrm{n}=50)$ & $25(50)$ & $19(38)$ & $6(12)$ & $34(68)$ & 0.00 & - & - \\
\hline \multirow{2}{*}{ Farzi et al. (11) } & \multirow{2}{*}{2014} & \multirow{2}{*}{ Iran } & \multirow{2}{*}{25} & Pethidine $(\mathrm{n}=65)$ & - & $18(27.6)$ & $6(9.2)$ & $41(63)$ & 0.00 & $59(90.7)$ & $65(100)$ \\
\hline & & & & $\operatorname{Control}(\mathrm{n}=65)$ & - & $35(53.8)$ & $9(13.8)$ & $35(53.8)$ & $2(3)$ & $62(95.3)$ & $65(100)$ \\
\hline \multirow{2}{*}{ Rastegarian (9) } & \multirow{2}{*}{2013} & & & $\begin{array}{l}\text { Pethidine }(\mathrm{n}= \\
50)\end{array}$ & $4(8)$ & $4(8)$ & $5(10)$ & $7(14)$ & 0.00 & $44(88)$ & $49(98)$ \\
\hline & & (IIIII & 23 & $\operatorname{Control}(\mathrm{n}=50)$ & $15(30)$ & 0.00 & 0.00 & $6(12)$ & 0.00 & $45(90)$ & $49(98)$ \\
\hline & & & & Pethidine $(\mathrm{n}=20)$ & 0.00 & $10(50 \%$ & $5(25)$ & $11(55)$ & $9(45)$ & $17(85)$ & $19(95)$ \\
\hline & & & 35 & $\operatorname{Control}(\mathrm{n}=20)$ & $10(50)$ & $10(50)$ & $5(25)$ & $13(65)$ & 0.00 & $18(90)$ & $20(100)$ \\
\hline Atalay er al. (24) & 2010 & Iurkey & 30 & Control $(\mathrm{n}=20)$ & $10(50)$ & $10(50)$ & $5(25)$ & $13(65)$ & 0.00 & $19(95)$ & $20(100)$ \\
\hline & & & & Pethidine $(\mathrm{n}=20)$ & 0.00 & $4(20)$ & $1(5)$ & $4(20)$ & $2(10)$ & $17(85)$ & $19(95)$ \\
\hline & & & $2 J$ & Control $(\mathrm{n}=20)$ & $10(50)$ & $10(50)$ & $5(25)$ & $13(65)$ & 0.00 & $18(90)$ & $19(95)$ \\
\hline & & & & Pethidine $(\mathrm{n}=20)$ & $3(15)$ & $11(55)$ & $11(55)$ & $14(70)$ & $5(25)$ & - & - \\
\hline & & & & Control $(\mathrm{n}=20)$ & $8(40)$ & $3(15)$ & $3(15)$ & $11(55)$ & 0.00 & - & - \\
\hline Kouzegaran et & - & Ient & - & Pethidine $(\mathrm{n}=20)$ & - & $16(80)$ & $16(80)$ & - & $3(15)$ & - & - \\
\hline al. (25) & & & & $\operatorname{Control}(\mathrm{n}=20)$ & - & $16(80)$ & $16(80)$ & - & 0.00 & - & - \\
\hline & & & & Pethidine ( $\mathrm{n}=98$ ) & $35(35.7)$ & $8(8.1)$ & $8(8.1)$ & $38(38.7)$ & 0.00 & - & - \\
\hline Kusumasari et & (2) & Jad & 10 & Control & . & . & . & . & - & - & . \\
\hline al. ((26) & 2013 & milonesid & (a) & Pethidine $(\mathrm{n}=98)$ & $22(22.4)$ & $22(22.4)$ & $22(22.4)$ & $48(48.9)$ & 0.00 & - & - \\
\hline & & & 20 & Control & - & - & - & - & - & - & - \\
\hline Hirmanpour et & 3017 & tem & 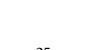 & $\begin{array}{l}\text { Pethidine }(\mathrm{n}= \\
40)\end{array}$ & $2(5)$ & $28(70)$ & $26(65)$ & $13(32.5)$ & $14(35)$ & $36(90)$ & $40(100)$ \\
\hline al. (27) & & Hait & 23 & Control $(\mathrm{n}=40)$ & $26(65)$ & $22(55)$ & $21(52.5)$ & $9(22.5)$ & $1(2.5)$ & $37(92.5)$ & $40(100)$ \\
\hline Zebetian et al. & & & & Pethidine $(\mathrm{n}=35)$ & $5(14.2)$ & . & . & $14(40)$ & 0.00 & $29(82.8)$ & $35(100)$ \\
\hline Mahmoud et al. & 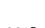 & & & Pethidine $(\mathrm{n}=30$ ) & $8(26.6)$ & $7(23.3)$ & $7(23.3)$ & - & $2(6.6)$ & $24(80)$ & $30(100)$ \\
\hline & 2010 & Lgypi & 10 & Control $(\mathrm{n}=30)$ & $20(66.6)$ & $3(10)$ & $3(10)$ & - & 0.00 & $25(83.3)$ & $29(96.6)$ \\
\hline Nasseri et al. & (2017 & Ien & 10 & Pethidine $(\mathrm{n}=30)$ & $2(6.6)$ & $12(40)$ & $6(20)$ & $20(66.6)$ & $1(3.3)$ & - & - \\
\hline (30) & 2011 & Hait & 10 & Control $(\mathrm{n}=30)$ & $18(60)$ & $10(33.3)$ & $5(16.6)$ & $21(70)$ & 0.00 & - & . \\
\hline 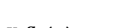 & & & & Pethidine $(\mathrm{n}=25)$ & - & $2(8)$ & $2(8)$ & $8(32)$ & $8(32)$ & $19(76)$ & $25(100)$ \\
\hline & 1575 & & 10 & Control $(\mathrm{n}=25)$ & & $2(8)$ & $2(8)$ & $15(60)$ & 0.00 & $19(76)$ & $25(100)$ \\
\hline Hong and Lee & 2005 & South & 10 & Pethidine $(\mathrm{n}=30)$ & $1(3.3)$ & $13(43.3)$ & $10(33.3)$ & - & $3(10)$ & $24(80)$ & $30(100)$ \\
\hline & & Korea & & $\operatorname{Control}(\mathrm{n}=30)$ & $7(23.3)$ & $11(36.6)$ & $8(26.6)$ & . & 0.00 & $27(90)$ & $30(100)$ \\
\hline & & & & Pethidine $(\mathrm{n}=39$ ) & $15(38.4)$ & $9(23)$ & $9(23)$ & $15(38.4)$ & $4(10)$ & $33(84.6)$ & $39(100)$ \\
\hline & & & 15 & Control $(\mathrm{n}=39)$ & $19(48.7)$ & $4(10)$ & 0.00 & $13(33.3)$ & 0.00 & $32(82)$ & $39(100)$ \\
\hline Anaraki and & - & 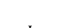 & 30 & Pethidine $(\mathrm{n}=39$ ) & $11(28.2)$ & $12(30.7)$ & $17(43.5)$ & $18(46.1)$ & $15(38.4)$ & $33(84.6)$ & $38(97.4)$ \\
\hline Mirzaei (8) & & & & $\operatorname{Control}(\mathrm{n}=39)$ & $19(48.7)$ & $4(10)$ & 0.00 & $13(33.3)$ & 0.00 & $34(87.1)$ & $39(100)$ \\
\hline & & & 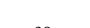 & Pethidine $(\mathrm{n}=39$ ) & $6(15.3)$ & $17(43.5)$ & $19(48.7)$ & $24(61.5)$ & $19(48.7)$ & $34(87.1)$ & $38(97.4)$ \\
\hline & & & & Control $(\mathrm{n}=39)$ & $19(48.7)$ & $4(10)$ & 0.00 & $13(33.3)$ & 0.00 & $34(87.1)$ & $39(100)$ \\
\hline & & & 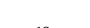 & Pethidine $(\mathrm{n}=24)$ & $9(37.5)$ & $10(41.6)$ & $7(29.1)$ & - & $3(12.5)$ & $17(70.8)$ & $22(91.6)$ \\
\hline Who & 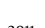 & Is & & Control $(\mathrm{n}=24)$ & $18(75)$ & $5(20.8)$ & $3(12.5)$ & - & 0.00 & $18(75)$ & $23(95.8)$ \\
\hline & & & 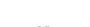 & Pethidine $(\mathrm{n}=24)$ & $2(8.3)$ & $15(62.5)$ & $13(54.1)$ & . & $3(12.5)$ & $18(75)$ & $22(91.6)$ \\
\hline & & & 25 & $\operatorname{Control}(\mathrm{n}=24)$ & $18(75)$ & $5(20.8)$ & $3(12.5)$ & - & 0.00 & $18(75)$ & $23(95.8)$ \\
\hline Shrestha et al. & 2007 & Nom & a & Pethidine $(\mathrm{n}=30)$ & $12(40)$ & $15(50)$ & $11(36.6)$ & - & $7(23.3)$ & - & - \\
\hline & & & & $\operatorname{Control}(\mathrm{n}=30)$ & $23(76.6)$ & $8(26.6)$ & $3(10)$ & . & 0.00 & . & . \\
\hline & & & & Pethidine $(\mathrm{n}=20)$ & $4(20)$ & $12(60)$ & $9(45)$ & . & $10(50)$ & . & . \\
\hline Koytail.(34) & 2004 & Candada & 15 & Control $(\mathrm{n}=20)$ & $15(75)$ & $7(35)$ & $2(10)$ & - & 0.00 & - & . \\
\hline Mohamed et al. & (200 & Fout & 2 & Pethidine $(\mathrm{n}=25)$ & $6(24)$ & $16(64)$ & $13(52)$ & - & $17(68)$ & - & - \\
\hline & & & $2 J$ & Control $(n=25)$ & $22(88)$ & $8(32)$ & $6(24)$ & - & $1(4)$ & - & - \\
\hline
\end{tabular}

${ }^{\mathrm{a}}$ Values are expressed as No. (\%). 


\begin{tabular}{|c|c|c|c|c|c|c|c|}
\hline \multirow{2}{*}{ Authors' Names } & \multirow{2}{*}{ Year } & \multirow{2}{*}{ Country } & \multirow{2}{*}{ Dose, $\mathrm{mg}$} & \multirow{2}{*}{$\begin{array}{l}\text { Pethidine/Control } \\
\text { (Number) }\end{array}$} & \multicolumn{3}{|c|}{ Variables } \\
\hline & & & & & $\begin{array}{l}\text { Time of Sensory } \\
\text { Block, min }\end{array}$ & $\begin{array}{l}\text { Time of Complete } \\
\text { Motor Block, min }\end{array}$ & $\begin{array}{c}\text { Analgesia } \\
\text { Duration, min }\end{array}$ \\
\hline \multirow{2}{*}{ Farzi et al. (11) } & \multirow{2}{*}{2014} & \multirow{2}{*}{ Iran } & \multirow{2}{*}{25} & Pethidine $(\mathrm{n}=65)$ & $4.5 \pm 0.51$ & $6.24 \pm 0.66$ & - \\
\hline & & & & Control $(n=65)$ & $5.13 \pm 0.29$ & $6.86 \pm 0.7$ & - \\
\hline \multirow{6}{*}{ Atalay et al. (24) } & \multirow{6}{*}{2010} & \multirow{6}{*}{ Turkey } & \multirow{2}{*}{35} & Pethidine $(\mathrm{n}=20)$ & $6.5 \pm 1.5$ & - & $403 \pm 43$ \\
\hline & & & & Control $(n=20)$ & $6.1 \pm 1.4$ & - & $185 \pm 20$ \\
\hline & & & \multirow{2}{*}{30} & Pethidine $(\mathrm{n}=20)$ & $6.9 \pm 1.7$ & - & $315 \pm 29$ \\
\hline & & & & Control $(\mathrm{n}=20)$ & $6.1 \pm 1.4$ & - & $185 \pm 20$ \\
\hline & & & \multirow{2}{*}{25} & Pethidine $(\mathrm{n}=20)$ & $7 \pm 1.7$ & - & $295 \pm 23$ \\
\hline & & & & Control $(n=20)$ & $6.1 \pm 1.4$ & - & $185 \pm 20$ \\
\hline \multirow{2}{*}{ Yu et al. (21) } & \multirow{2}{*}{2002} & \multirow{2}{*}{ China } & \multirow{2}{*}{10} & Pethidine $(\mathrm{n}=20)$ & - & - & $234 \pm 25$ \\
\hline & & & & Control $(n=20)$ & - & - & $125 \pm 12$ \\
\hline \multirow{2}{*}{$\begin{array}{l}\text { Kouzegaran et al. } \\
\text { (25) }\end{array}$} & \multirow{2}{*}{2018} & \multirow{2}{*}{ Iran } & \multirow{2}{*}{5} & Pethidine $(\mathrm{n}=20)$ & - & - & $139 \pm 45$ \\
\hline & & & & Control $(n=20)$ & - & - & $87.6 \pm 30$ \\
\hline \multirow{2}{*}{$\begin{array}{l}\text { Zebetian et al. } \\
\text { (28) }\end{array}$} & \multirow{2}{*}{2013} & \multirow{2}{*}{ Iran } & \multirow{2}{*}{10} & Pethidine $(\mathrm{n}=35)$ & - & $6.95 \pm 1.4$ & - \\
\hline & & & & Control $(\mathrm{n}=35)$ & - & $7.35 \pm 1.10$ & - \\
\hline \multirow{2}{*}{ Kafle (31) } & \multirow{2}{*}{1993} & \multirow{2}{*}{ Nepal } & \multirow{2}{*}{10} & Pethidine $(\mathrm{n}=25)$ & $5 \pm 2$ & - & - \\
\hline & & & & Control $(\mathrm{n}=25)$ & $5 \pm 2$ & - & - \\
\hline Heng and Lee (32) & 2005 & South Korea & 10 & Pethidine $(\mathrm{n}=30)$ & $4.8 \pm 0.2$ & $7.1 \pm 1.5$ & - \\
\hline Hong antu tec (32) & 2005 & 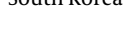 & 10 & Control $(\mathrm{n}=30)$ & $5.75 \pm 0.3$ & $7.2 \pm 1.7$ & - \\
\hline Shrestha et al. & 2007 & Nepal & 10 & Pethidine $(\mathrm{n}=30)$ & - & - & $510 \pm 32$ \\
\hline (23) & 200 & & to & Control $(\mathrm{n}=30)$ & - & - & $96 \pm 12$ \\
\hline Poyet al (24) & 2000 & Conods & 15 & Pethidine $(\mathrm{n}=20)$ & $4.5 \pm 0.41$ & $6.75 \pm 0.21$ & \\
\hline (Koy et dit. (34) & 2004 & Calldud & 13 & Control $(n=20)$ & $5.1 \pm 0.39$ & $6.95 \pm 0.29$ & \\
\hline Mohamad et al. & 2018 & Fovont 120 & 25 & Pethidine $(\mathrm{n}=25)$ & - & - & $169.2 \pm 7.59$ \\
\hline (35) & 2018 & Lgypt & 23 & Control $(\mathrm{n}=25)$ & - & - & $93 \pm 17$ \\
\hline
\end{tabular}

${ }^{a}$ Values are expressed as mean \pm SD.

\begin{tabular}{|c|c|c|c|c|c|}
\hline Parameters & Sample Size & Number of Study & $\mathbf{I}^{2}, \%$ & $\mathbf{R R}(95 \% \mathrm{CI})$ & $\mathbf{P}$ \\
\hline Shivering (dose $\leq 20$ ) & 720 & 12 & 61.6 & $0.34(0.23,0.48)$ & 0.003 \\
\hline Shivering $($ dose $>20)$ & 440 & 8 & 62.9 & $0.18(0.09,0.39)$ & 0.009 \\
\hline Nausea $($ dose $\leq 20)$ & 690 & 12 & 10.2 & $1.37(1.13,1.66)$ & 0.345 \\
\hline Nausea $($ dose $>20)$ & 520 & 9 & 69.8 & $1.33(0.88,2.02)$ & 0.001 \\
\hline Vomiting $($ dose $\leq 20)$ & 670 & 12 & 60.5 & $2.02(1.28,3.20)$ & 0.003 \\
\hline Vomiting (dose > 20) & 520 & 9 & 72.8 & $1.57(0.78,3.17)$ & 0.000 \\
\hline Hypotension (dose $\leq 20$ ) & 450 & 7 & 0.00 & $1.00(0.87,1.15)$ & 0.473 \\
\hline Hypotension $($ dose $>20)$ & 517 & 8 & 62.8 & $1.01(0.72,1.43)$ & 0.009 \\
\hline Pruritus $($ dose $\leq \mathbf{2 0})$ & 760 & 12 & 0.00 & $9.26(4.17,20.58)$ & 0.999 \\
\hline Pruritus $($ dose $>20)$ & 490 & 8 & 0.00 & $17.77(7.34,43.00)$ & 0.986 \\
\hline Apgar $>7$ at $1 \mathrm{~min}($ dose $\leq 20)$ & 370 & 6 & 0.00 & $0.99(0.9,1.09)$ & 0.996 \\
\hline Apgar $>7$ at $1 \mathrm{~min}($ dose $>20)$ & 568 & 9 & 0.00 & $0.96(0.92,1.02)$ & 1.000 \\
\hline Apgar $>7$ at $5 \mathrm{~min}($ dose $\leq 20)$ & 340 & 6 & 0.00 & $0.93(0.87,1.08)$ & 0.687 \\
\hline Apgar $>7$ at $5 \mathrm{~min}($ dose $>20)$ & 570 & 6 & 0.00 & $0.99(0.95,1.02)$ & 0.889 \\
\hline
\end{tabular}

Abbreviations: $\mathrm{CI}$, confidence interval; $\mathrm{I}^{2}$, I-squared; RR, relative risk (random effects models and fixed effects models).

dine with a dose of $\leq 20$ on nausea was not significant in 11 studies except for one study. The final result was significant with a total composition of the 12 studies. The weight of the Shami et al. (10) study was more than other studies. The rate of nausea resulted from the pethidine with dose $>$ 20 was not significant in 9 studies (Table 3 and Figure 3 ). In 


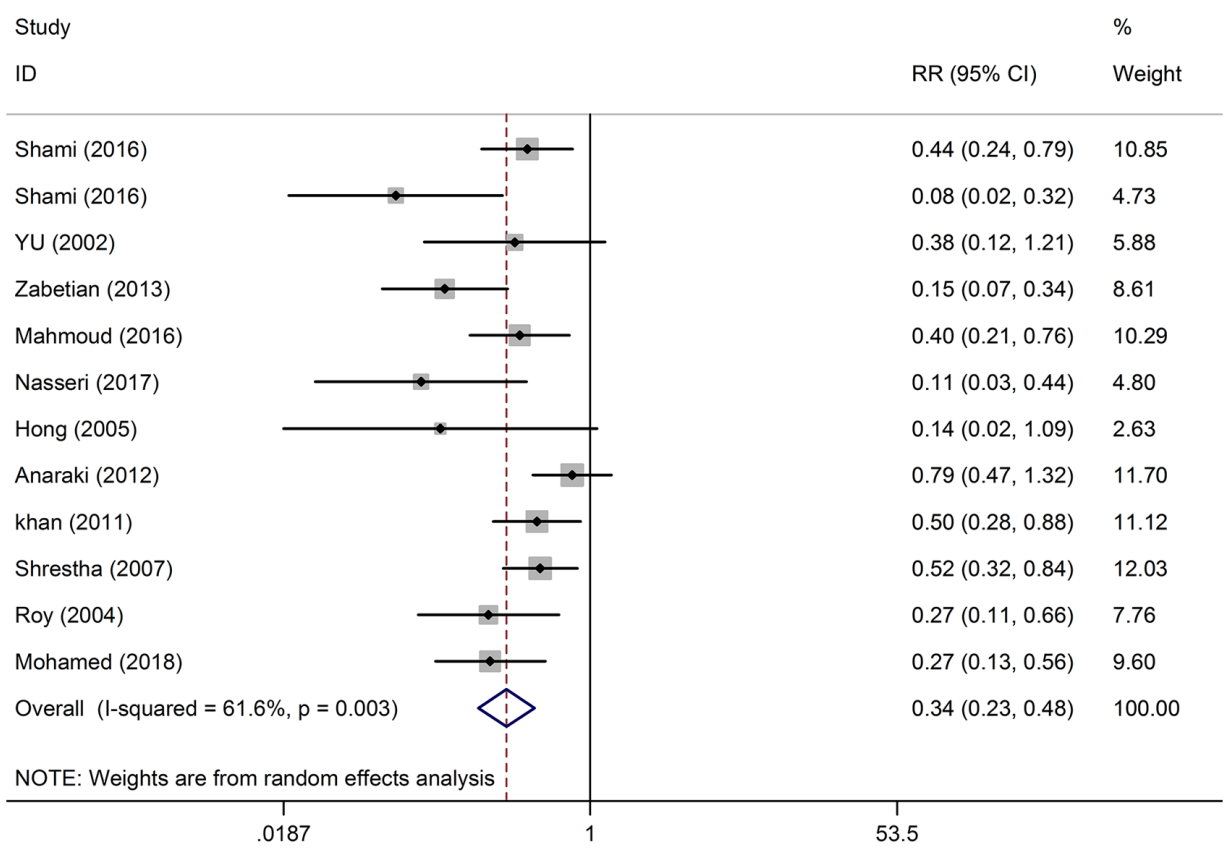

Figure 2. Chart of shivering with dose $\leq 20 \mathrm{mg}$ of pethidine

the 12 studies, the effect of the intrathecal pethidine with a dose of $\leq 20$ on vomiting and postoperative pruritus was significant. Those who had received pethidine at a dose of $\leq 20$ experienced pruritus $26 \%$ more. In nine of the studies on the effect of intrathecal pethidine with a dose of $>$ 20 on vomiting, not a significant difference was observed. While nine of the studies on the effect of the intrathecal pethidine with a dose of $>20$ on pruritus showed a meaningful difference. Here, $77 \%$ of those who had received the pethidine at a dose of $>20$ showed more pruritus (Table 3 ).

The results of the analysis of the studies with different doses indicated that the intrathecal pethidine had no effect on the neonate Apgar score, maternal sensory and motor block time; and no significant effect was found in the study of these variables (Tables 3 and 4 and Figure 4). In the three studies, the effect of intrathecal pethidine with a dose of $\leq 20$ on the duration of the postoperative analgesia was significant. Those who received pethidine had $67 \%$ more analgesic duration (Table 4). The funnel plot showed that the effect of bias was not meaningful confirming that the studies with positive and negative results had a chance to print and have been included in the study (Figure 5). The meta-analysis showed that the new studies were less effective (Figure 6).

\section{Discussion}

In this study, we evaluated the effects of different doses of the intrathecal pethidine ( 5 to $40 \mathrm{mg}$ ) on the maternal and newborn parameters during the cesarean section under the spinal anesthesia. Our study showed that administration of the intrathecal pethidine in the cesarean patients with under the spinal anesthesia can reduce the postoperative shivering so that the more the doses of the pethidine, the more the reduction in the shivering. The intrathecal pethidine in the pethidine group increases the relative risk of nausea, vomiting, and pruritus after the surgery in the patients with the cesarean delivery. With the increased doses of pethidine, the relative risk of pruritus gets higher in the cesarean section. The results of the analysis of the studies with different doses indicated that the intrathecal pethidine had no effect on the newborn Apgar score, mother's hypotension, and the maternal time of the motor and sensory block. On the other hand, mothers of the cesarean section who had received pethidine under the spinal anesthesia had more duration of analgesia after the surgery.

In a meta-analysis by Lin et al. (20) on the effect of the intrathecal pethidine $(5 / 25 \mathrm{mg}$ ) on various surgeries, they revealed that a minimum dose of pethidine reduced significantly shivering and increased the demand for sedatives; however, the risk of nausea and vomiting is increased 


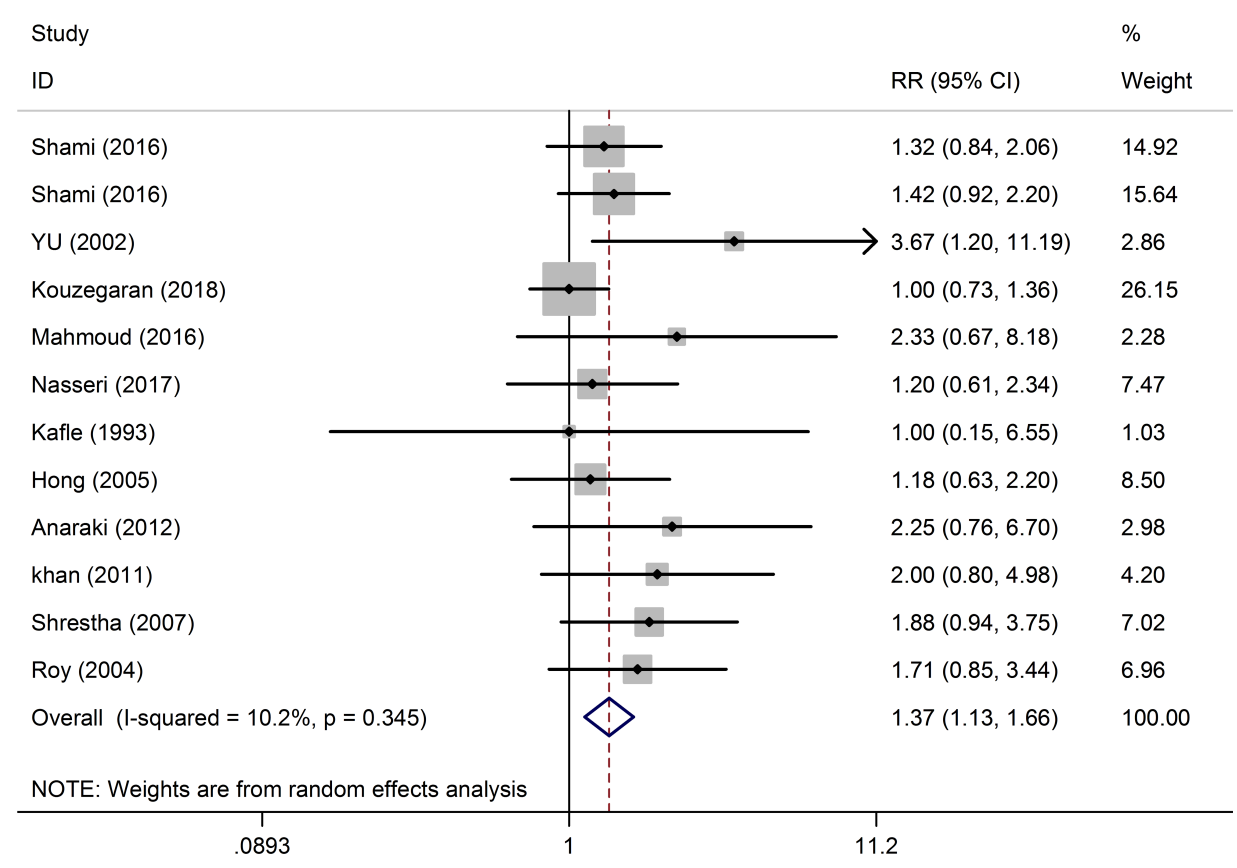

Figure 3. Chart of nausea with dose $\leq 20 \mathrm{mg}$ of pethidine

\begin{tabular}{|c|c|c|c|c|c|}
\hline Parameters & Sample Size & Number of Study & $\mathbf{I}^{\mathbf{2}}, \%$ & $\operatorname{SMD}(95 \% \mathrm{CI})$ & $\mathbf{P}$ \\
\hline Time of sensory block (dose $\leq 20$ ) & 150 & 3 & 96.2 & $-1.72(-3.78,0.34)$ & 0.00 \\
\hline Time of sensory block $($ dose $>20)$ & 210 & 4 & 94.3 & $0.05(-1.11,1.22)$ & 0.00 \\
\hline Time of complete motor block (dose $\leq \mathbf{2 0}$ ) & 100 & 2 & 96.6 & $-4.38(-9.19,0.44)$ & 0.00 \\
\hline Time of complete motor block (dose $>20$ ) & - & - & - & - & - \\
\hline Analgesia duration $($ dose $\leq \mathbf{2 0})$ & 140 & 3 & 97.9 & $7.67(1.85,13.49)$ & 0.00 \\
\hline Analgesia duration $($ dose $>20)$ & - & - & - & - & - \\
\hline
\end{tabular}

Abbreviation: SMD, standard mean difference (random effects models and fixed effects models).

in the patient. Studies carried out by Popping et al. (36), Shami et al. (10), Rastegarian et al. (9), and Nasseri et al. (30) all suggested the intrathecal anti-shivering effect of the opiates, that are consistent with the results of the present study.

Shivering during the spinal anesthesia owns a multifactor mechanism. The sympathetic block, due to the spinal anesthesia, causes disturbance compensatory vasoconstriction and automatic adjustment below the level of blockage and slows down the thermoregulation, which leads ultimately to the vasodilatation and hypothermia. All these factors contribute finally to shivering $(37,38)$.

Pethidine is one of the most commonly used drugs for treating and preventing both shivering and pain, which is more effective in controlling these two rather than the other sedatives $(20,39)$. Although the mechanism of the effect of pethidine on shivering and pain control is not clear, it may be probably due to its direct effect on the temperature regulation center or its agonistic effects on the sedative receptors of $\mu$ and $(40,41)$.

In the study of Shami et al. (10), Farzi et al. (11), and Rastegarian et al. (9), there was no statistically significant difference in nausea and vomiting between the two pethidine and control groups. On the contrary, Lin et al. (20) reported the increased risk of nausea and vomiting in their meta-analysis, which is consistent with the results in the present study.

In our study out of 12 studies on the effect of intrathecal pethidine with a dose of $20 \mathrm{mg}$ or less on nausea, only one study was significant while the rest 11 ones were not. On the 


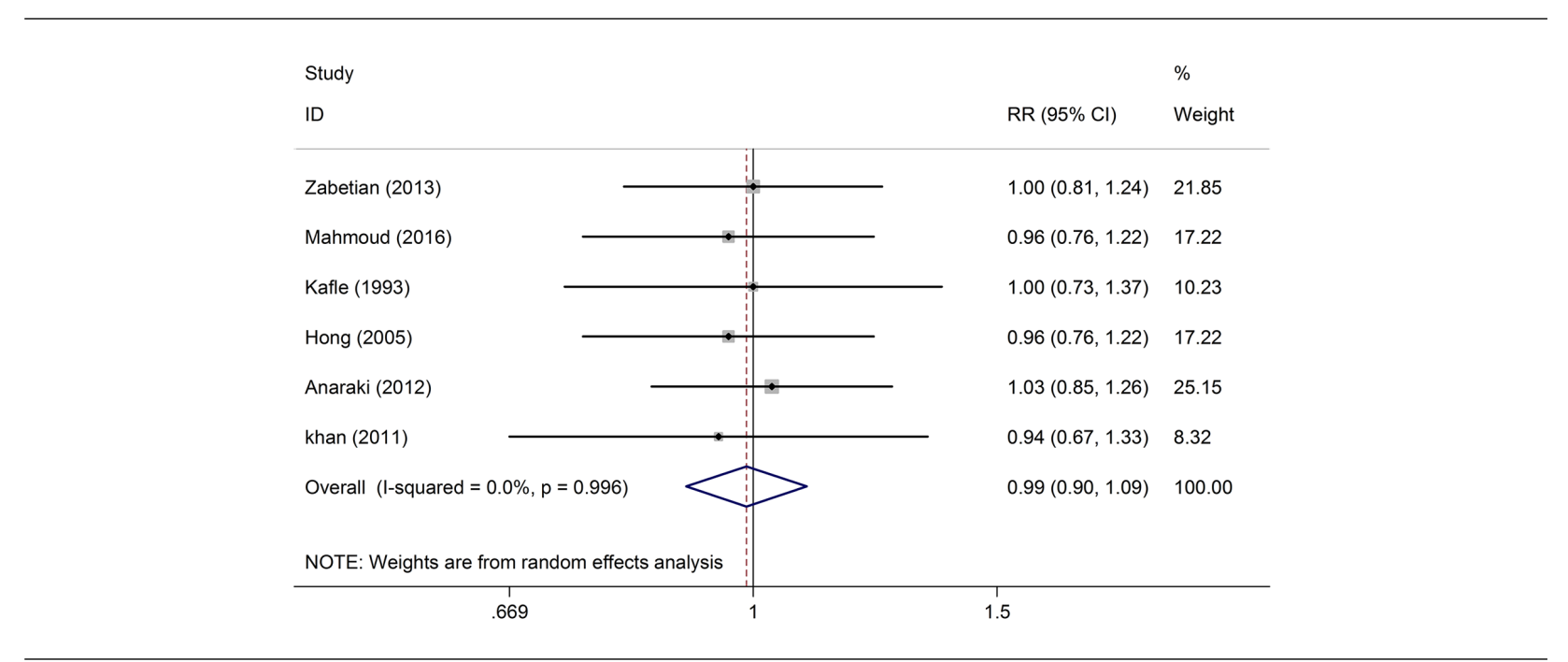

Figure 4. Chart of Apgar score $>7$ at 1 min with dose $\leq 20 \mathrm{mg}$ of pethidine

Begg's Funnel Plot with Pseudo 95\% Confidence Limits

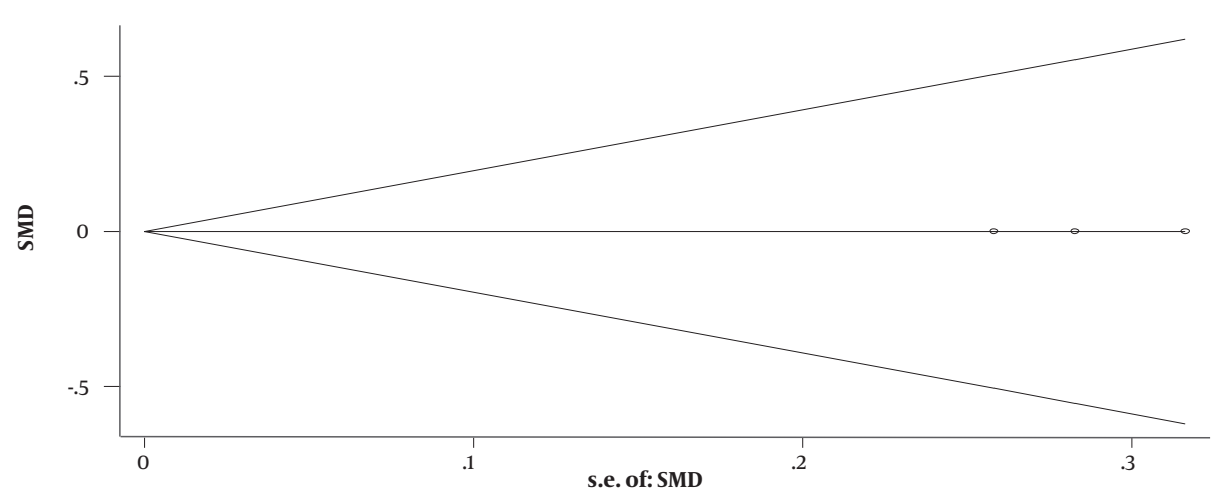

Note: default data input format (theta, se_theta) assumed. Tests for Publication Bias

Begg's Test

adj. Kendall's Score $(\mathrm{P}-\mathrm{Q})=\mathrm{O}$

Std. Dev. of Score $=2.71$ (corrected for ties)

Number of Studies $=3$

$\begin{aligned} z & =0.00 \\ \operatorname{Pr}>|z| & =1.000\end{aligned}$

$z=-0.37$ (continuity corrected)

$\operatorname{Pr}>|z|=1.000$ (continuity corrected)

\begin{tabular}{r|rrrrrr}
\multicolumn{1}{l}{ Egger's test } \\
\hline Std_Eff & Coef. & std. & Err. & t & $\mathrm{P}>|\mathrm{t}|$ & [95\% Conf. Interval] \\
\hline $\begin{array}{r}\text { slope } \\
\text { bias }\end{array}$ & $\begin{array}{r}\text { (dropped) } \\
\text { (dropped) }\end{array}$ & & & & & \\
\hline
\end{tabular}

Figure 5. Chart of funnel plot

whole, as far as the 12 studies are concerned, the difference was meaningful. One of the benefits of the meta-analysis 


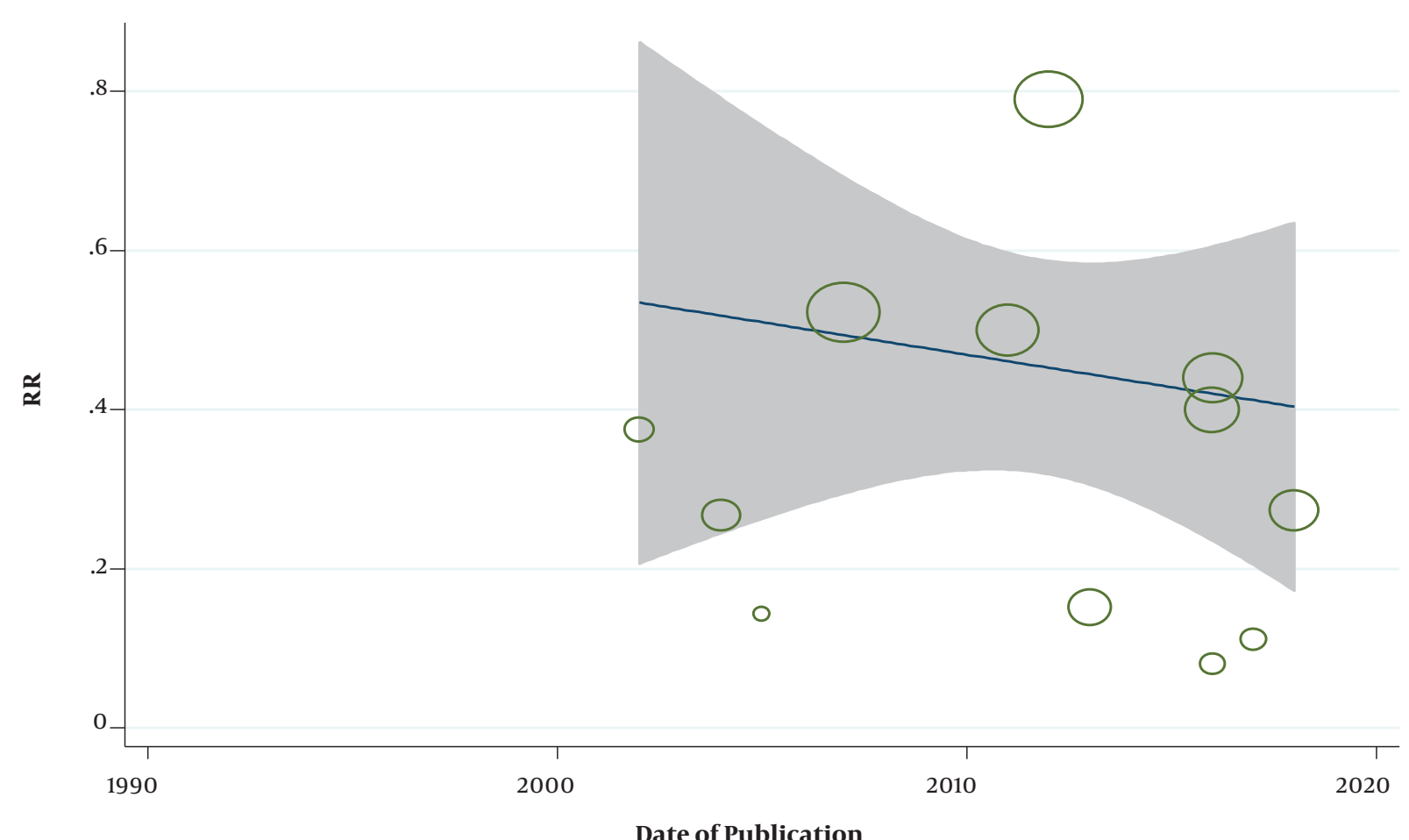

Meta-regression

REML estimate of between-study variance

$\%$ residual variation due to heterogeneity

Proportion of between-study variance explained

With Knapp-Hartung modification

Number of obs $=\quad 12$

tau2 $=0$

I -squared_res $=0.00 \%$

Adj R-squared $=\quad \%$

\begin{tabular}{|c|c|c|c|c|c|c|}
\hline -ES & Coef. & Std. Err. & $\mathrm{t}$ & $\mathrm{P}>|\mathrm{t}|$ & \multicolumn{2}{|c|}{ [ 95\% Conf. Interval ] } \\
\hline publication & -.0081643 & .0240436 & -0.34 & 0.741 & -.0617369 & 0454083 \\
\hline- cons & 16.87929 & 48.37157 & 0.35 & 0.734 & -90.89928 & 124.6579 \\
\hline
\end{tabular}

Figure 6. Chart of publication bias

studies is that in the separate studies due to the low sample size in each study, even high effect sizes may not be significant. For example, nausea had an effect size greater than 2 in 4 studies which was not considered as significant due to the low number of the samples in each study, but when the 12 studies were combined altogether, because of the increases sample sizes, the effect size turns out significant showing that nausea was 37\% higher in the patients taking pethidine. The same applies to vomiting.

Like other narcotics, pethidine has side effects such as respiratory depression, hypotension, nausea, vomiting, decreased gastrointestinal motility, and physical dependency (41). The increase in nausea and vomiting just fol- lowed by the administration of intrathecal pethidine is resulted from multiple issues. Firstly, the intrathecal pethidine may act as an independent analgesic. Therefore, when it is combined with a high level of anesthesia, it can lead to a decrease in systemic blood pressure along with vomiting and nausea. On the other hand, pethidine like other narcotics has central effects on nausea and vomiting $(20,21)$.

In a series of studies $(10,24)$, the rate of pruritus following the intrathecal pethidine was significant, while it was not significant in some other studies $(9,11,32)$. This difference may be due to the administration of the pethidine dose. In our meta-analysis, with an increased dose of pethidine, the relative risk of pruritus was increased. 
In the study of Zebetian et al. (28), Hong and Lee (32), and Anaraki and Mirzaei (8), there was no significant difference in the newborn Apgar score, which is quite consistent with the present study. There was no significant difference in the duration of the sensory and motor blocks in the mothers with the cesarean section, which is in line with the studies performed by Hong and Lee (32) and Roy et al. (34). In our study, the mothers who had received the intrathecal pethidine had longer duration analgesia after the surgery, which was consistent with the results reported by Kouzegaran et al. (25), Shrestha et al. (23), and Yu et al. (21).

\subsection{Limitations and Strengths}

The small number of studies in this meta-analysis is one of the limitations; however, there has been no bias in the inclusion of the studies in this meta-analysis. The absence of language constraints in entering the studies and including the entire parameters of the studies in the metaanalysis are among the strengths of this study.

\section{Acknowledgments}

We thank Vice-Chancellor for research at Tehran and Ilam University of Medical Sciences.

\section{Footnotes}

Authors' Contribution: Molouk Jaafarpour and Ziba Taghizadeh participated in the study design, literature review, preparing, and editing the manuscript. Kourosh Sayehmiri participated in the data analysis preparation and editing the manuscript. Elham Shafiei and Aminolah Vasigh participated in the study design, data collection preparation, and editing the manuscript. All the authors read, edited, and approved the final version.

Conflict of Interests: There is no conflict of interest.

Funding/Support: Tehran University of Medical Sciences financially supported this study.

\section{References}

1. Bilgen S, Koner O, Ture H, Menda F, Ficicioglu C, Aykac B. Effect of three different doses of ketamine prior to general anaesthesia on postoperative pain following Caesarean delivery: A prospective randomized study. Minerva Anestesiol. 2012;78(4):442-9. [PubMed: 22240615].

2. Conde-Agudelo A, Nieto A, Rosas-Bermudez A, Romero R. Misoprostol to reduce intraoperative and postoperative hemorrhage during cesarean delivery: A systematic review and metaanalysis. Am J Obstet Gynecol. 2013;209(1):40 e1-40 e17. doi: 10.1016/j.ajog.2013.03.015. [PubMed: 23507545]. [PubMed Central: PMC3731410].

3. Jaafarpour M, Vasigh A, Khajavikhan J, Khani A. Effect of ketofol on pain and complication after caesarean delivery under spinal anaesthesia: A randomized double-blind clinical trial. J Clin Diagn Res. 2017;11(3):UC04-7. doi: 10.7860/JCDR/2017/21437.9434. [PubMed: 28511482]. [PubMed Central: PMC5427408].
4. Beiranvand S, Noparast M, Eslamizade N, Saeedikia S. The effects of religion and spirituality on postoperative pain, hemodynamic functioning and anxiety after cesarean section. Acta Med Iran. 2014;52(12):909-15. [PubMed: 25530054].

5. Zamani-Alavijeh F, Araban M, Hassanzadeh A, Makhouli K. Contributing factors of pregnant women's beliefs towards mode of delivery: A cross-sectional study from Iran. Matern Health Neonatol Perinatol. 2018;4:9. doi: 10.1186/s40748-018-0077-1. [PubMed: 29744129]. [PubMed Central: PMC5930689].

6. Rafiei M, Saei Ghare M, Akbari M, Kiani F, Sayehmiri F, Sayehmiri $\mathrm{K}$, et al. Prevalence, causes, and complications of cesarean delivery in Iran: A systematic review and meta-analysis. Int $J$ Reprod Biomed (Yazd). 2018;16(4):221-34. [PubMed: 29942930]. [PubMed Central: PMC6004597].

7. Betran AP, Merialdi M, Lauer JA, Bing-Shun W, Thomas J, Van Look $P$, et al. Rates of caesarean section: Analysis of global, regional and national estimates. Paediatr Perinat Epidemiol. 2007;21(2):98-113. doi: 10.1111/j.1365-3016.2007.00786.x. [PubMed: 17302638].

8. Anaraki AN, Mirzaei K. The effect of different intrathecal doses of meperidine on shivering during delivery under spinal anesthesia. Int J Prev Med. 2012;3(10):706-12. [PubMed: 23112897]. [PubMed Central: PMC3482998].

9. Rastegarian A, Ghobadifar MA, Kargar H, Mosallanezhad Z. Intrathecal meperidine plus lidocaine for prevention of shivering during cesarean section. Korean J Pain. 2013;26(4):379-86. doi: 10.3344/kjp.2013.26.4.379. [PubMed: 24156005]. [PubMed Central: PMC3800711].

10. Shami S, Nasseri K, Shirmohammadi M, Sarshivi F, Ghadami N, Ghaderi E, et al. Effect of low dose of intrathecal pethidine on the incidence and intensity of shivering during cesarean section under spinal anesthesia: A randomized, placebo-controlled, double-blind clinical trial. Drug Des Devel Ther. 2016;10:3005-12. doi: 10.2147/DDDT.S115201. [PubMed: 27703328]. [PubMed Central: PMC5036596].

11. Farzi F, Mirmansouri A, Forghanparast K, Heydarzadeh A, Abdollahzadeh M, Jahanyar Moghadam F. Addition of intrathecal fentanyl or meperidine to lidocaine and epinephrine for spinal anesthesia in elective cesarean delivery. Anesth Pain Med. 2014;4(1). e14081. doi: 10.5812/aapm.14081. [PubMed: 24701418]. [PubMed Central: PMC3961034].

12. Edipoglu IS, Celik F, Marangoz EC, Orcan GH. Effect of anaesthetic technique on neonatal morbidity in emergency caesarean section for foetal distress. PLoS One. 2018;13(11). e0207388. doi: 10.1371/journal.pone.0207388. [PubMed: 30444916]. [PubMed Central: PMC6239306].

13. Tumukunde J, Lomangisi DD, Davidson O, Kintu A, Joseph E, Kwizera A. Effects of propofol versus thiopental on Apgar scores in newborns and peri-operative outcomes of women undergoing emergency cesarean section: A randomized clinical trial. BMC Anesthesiol. 2015;15:63. doi: 10.1186/s12871-015-0044-6. [PubMed: 25924776]. [PubMed Central: PMC4419384].

14. Jarineshin H, Fekrat F, Kashani S. The effect of paracetamol versus meperidine on postoperative pain of cesarean section. Anesth Essays Res. 2017;11(1):165-8. doi: 10.4103/0259-1162.186617. [PubMed: 28298778]. [PubMed Central: PMC5341656].

15. Lee YZ, Lee RQ, Thinn KK, Poon KH, Liu EH. How patients fare after anaesthesia for elective surgery: A survey of postoperative nausea and vomiting, pain and confusion. Singapore Med J. 2015;56(1):40-6. doi: 10.11622/smedj.2015008. [PubMed: 25640098]. [PubMed Central: PMC4325575].

16. Vasigh A, Najafi F, Khajavikhan J, Jaafarpour M, Khani A. Comparing gabapentin and celecoxib in pain management and complications after laminectomy: A randomized double-blind clinical trial. Iran Red Crescent Med J. 2016;18(2). e34559. doi: 10.5812/ircmj.34559. [PubMed: 27195145]. [PubMed Central: PMC4867363]. 
17. Vasigh A, Jaafarpour M, Khajavikhan J, Khani A. The effect of gabapentin plus celecoxib on pain and associated complications after laminectomy. J Clin Diagn Res. 2016;10(3):UC04-8. doi: 10.7860/JCDR/2016/17923.7346. [PubMed: 27134973]. [PubMed Central: PMC4843358].

18. Faiz SH, Rahimzadeh $\mathrm{P}$, Imani F, Bakhtiari A. Intrathecal injection of magnesium sulfate: shivering prevention during cesarean section: A randomized, double-blinded, controlled study. Korean J Anesthesiol. 2013;65(4):293-8. doi: 10.4097/kjae.2013.65.4.293. [PubMed: 24228140]. [PubMed Central: PMC3822019].

19. Cakirtekin V, Yildirim A, Bakan N, Celebi N, Bozkurt O. Comparison of the effects of thiopental sodium and propofol on haemodynamics, awareness and newborns during caesarean section under general anaesthesia. Turk J Anaesthesiol Reanim. 2015;43(2):106-12. doi: 10.5152/T]AR.2014.75547. [PubMed: 27366476]. [PubMed Central: PMC4917150].

20. Lin YC, Chen CY, Liao YM, Liao AH, Lin PC, Chang CC. Preventing shivering with adjuvant low dose intrathecal meperidine: A metaanalysis of randomized controlled trials with trial sequential analysis. Sci Rep. 2017;7(1):15323. doi: 10.1038/s41598-017-14917-5. [PubMed: 29127294]. [PubMed Central: PMC5681692].

21. Yu SC, Ngan Kee WD, Kwan AS. Addition of meperidine to bupivacaine for spinal anaesthesia for Caesarean section. Br J Anaesth. 2002;88(3):379-83. doi: 10.1093/bja/88.3.379. [PubMed: 11990270].

22. Liberati A, Altman DG, Tetzlaff J, Mulrow C, Gotzsche PC, Ioannidis JP, et al. The PRISMA statement for reporting systematic reviews and meta-analyses of studies that evaluate health care interventions: Explanation and elaboration. PLoS Med. 2009;6(7). e1000100. doi: 10.1371/journal.pmed.1000100. [PubMed:19621070]. [PubMed Central: PMC2707010].

23. Shrestha BR, Maharjan SK, Thapa C. Comparative study between bupivacaine heavy vs pethidine intrathecally to study early haemodynamic changes and postoperative analgesia in patients undergoing caesarean section. Kathmandu Univ Med J (KUMJ). 2007;5(2):166-72. [PubMed: 18604013].

24. Atalay C, Aksoy M, Aksoy AN, Dogan N, Kursad H. Combining intrathecal bupivacaine and meperidine during caesarean section to prevent spinal anaesthesia-induced hypotension and other side-effects. J Int Med Res. 2010;38(5):1626-36. doi: 10.1177/147323001003800507. [PubMed: 21309476].

25. Kouzegaran S, Ganjifard M, Sabertanha A. Effects of adding $5 \mathrm{mg}$ meperidine to $10 \mathrm{mg}$ bupivacaine for spinal anesthesia on postoperative pain in cesarean section surgery. J Surg Trauma. 2018;6(1):1-5.

26. Kusumasari NH, Artika IGNR, Sari D. Efficacy of pethidine 0.1 and 0.2 $\mathrm{mg} / \mathrm{kg}$ body weight as an adjuvant of intrathecal bupivacaine $0.5 \%$ $10 \mathrm{mg}$ in preventing shivering. J Thee Med Sci. 2013;45(4):187-95. doi: 10.19106/JMedScie004504201305.

27. Hirmanpour A, Talakoub R, Shafa A, Chitsaz N. Evaluating the effect of intrathecal sufentanil and meperidine on shivering after caesarean section under spinal anesthesia. Arch Anesthesiol Critic Care. 2017;3(4):365-72.

28. Zabetian H, Sotoodeh Jahromi A, Karami MY, Ghobadifar MA. Antishivering effect of low dose meperidine in caesarean section under spinal anesthesia: A randomized double-blind placebo-controlled trial. Int J Pharmacol. 2013;9(5):305-11. doi:10.3923/ijp.2013.305.311.

29. Mahmoud MS, Kamal MM, Abdellatif AM, Elfawal SM. Effect of in- trathecal meperidine and intravenous amino acid infusion in reducing intraoperative shivering during spinal anesthesia: A prospective randomized trial. Egypt J Anaesthesia. 2019;32(3):391-6. doi: 10.1016/j.egja.2016.04.005.

30. Nasseri K, Ghaderi E, Khezripour E. Comparison of the effects of intrathecal meperidine and morphine on incidence and intensity of shivering after caesarean sections under spinal anesthesia: A randomized controlled trial. Iran Red Crescent Med J. 2017;19(7). e55567. doi: $10.5812 /$ ircmj.55567.

31. Kafle SK. Intrathecal meperidine for elective caesarean section: A comparison with lidocaine. Can J Anaesth. 1993;40(8):718-21. doi: 10.1007/BF03009767. [PubMed: 8403155].

32. Hong JY, Lee IH. Comparison of the effects of intrathecal morphine and pethidine on shivering after Caesarean delivery under combined-spinal epidural anaesthesia. Anaesthesia. 2005;60(12):116872. doi: 10.1111/j.1365-2044.2005.04158.x. [PubMed: 16288613].

33. Khan ZH, Zanjani AP, Makarem J, Samadi S. Antishivering effects of two different doses of intrathecal meperidine in caesarean section: A prospective randomised blinded study. Eur J Anaesthesiol. 2011;28(3):202-6. doi: 10.1097/EJA.0b013e3283430802. [PubMed: 21325901].

34. Roy JD, Girard M, Drolet P. Intrathecal meperidine decreases shivering during cesarean delivery under spinal anesthesia. Anesth Analg. 2004;98(1):230-4. table of contents. doi: 10.1213/01.ane.0000093251.42341.74. [PubMed: 14693625].

35. Mohamed G, Ahmed NSH, Hameed A, Adel GE, El Sabaa AAR. Comparative study between the addition of pethidine Vs fentanyl to hyperbaric bupivacaine for spinal anesthesia in caesarean section. Egypt J Hosp Med. 2018;73(1):5813-7.

36. Popping DM, Elia N, Wenk M, Tramer MR. Combination of a reduced dose of an intrathecal local anesthetic with a small dose of an opioid: A meta-analysis of randomized trials. Pain. 2013;154(8):1383-90. doi: 10.1016/j.pain.2013.04.023. [PubMed: 23731835].

37. Crowley LJ, Buggy DJ. Shivering and neuraxial anesthesia. Reg Anesth Pain Med.2008;33(3):241-52.doi:10.1016/j.rapm.2007.11.006. [PubMed: 18433676].

38. Sessler DI. Temperature monitoring and perioperative thermoregulation. Anesthesiology. 2008;109(2):318-38. doi: 10.1097/ALN.ob013e31817f6d76. [PubMed: 18648241]. [PubMed Central: PMC2614355].

39. Kranke P, Eberhart LH, Roewer N, Tramer MR. Pharmacological treatment of postoperative shivering: A quantitative systematic review of randomized controlled trials. Anesth Analg. 2002;94(2):453-60. table of contents. doi: 10.1097/00000539-200202000-00043. [PubMed: 11812718].

40. Eydi M, Golzari SEJ, Aghamohammadi D, Kolahdouzan KH, Safari S, Ostadi Z. Postoperative management of shivering: A comparison of pethidine vs. ketamine. Anesth Pain Med. 2014;4. e15499. doi: 10.5812/aapm.15499.

41. Khezri MB, Mosallaei MA, Ebtehaj M, Mohammadi N. Comparison of preemptive effect of intravenous ketorolac versus meperidine on postoperative shivering and pain in patients undergoing cesarean section under spinal anesthesia: A prospective, randomized, double-blind study. Caspian J Intern Med. 2018;9(2):151-7. doi: 10.22088/cjim.9.2.151. [PubMed: 29732033]. [PubMed Central: PMC5912223]. 